\title{
Aa. Vv., Le point sur l'espace francophone
}

\section{Francesca Torchi}

\section{(2) OpenEdition}

\section{Journals}

\section{Edizione digitale}

URL: http://journals.openedition.org/studifrancesi/36756

DOI: 10.4000/studifrancesi.36756

ISSN: 2421-5856

\section{Editore}

Rosenberg \& Sellier

\section{Edizione cartacea}

Data di pubblicazione: 1 juillet 2005

Paginazione: 203-204

ISSN: 0039-2944

\section{Notizia bibliografica digitale}

Francesca Torchi, «Aa. VV., Le point sur l'espace francophone», Studi Francesi [Online], 145 (XLIX | I) |

2005, online dal 30 novembre 2015, consultato il 20 avril 2021. URL: http://journals.openedition.org/ studifrancesi/36756 ; DOI: https://doi.org/10.4000/studifrancesi.36756

\section{Questo documento è stato generato automaticamente il 20 avril 2021.}

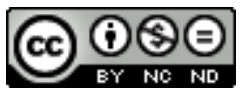

Studi Francesi è distribuita con Licenza Creative Commons Attribuzione - Non commerciale - Non opere derivate 4.0 Internazionale. 


\title{
Aa. Vv., Le point sur l'espace francophone
}

\author{
Francesca Torchi
}

\section{NOTIZIA}

«L'Année Francophone Internationale », Le point sur l'espace francophone, 2004, pp. 413.

Con il termine francofonia si indica un fenomeno in continua evoluzione e dalle sfaccettature più diverse, non legato soltanto a una lingua e a una cultura ma al progressivo ed eterogeneo sviluppo delle aree francofone, ognuna con le proprie peculiarità. In quest'ottica la rivista AFI propone un panorama dello stato delle aree francofone. Come ogni volume, anche quello del 2004 presenta una prima parte generale - Pays et régions - suddivisa per aree geografiche, una mise à jour dei dati già forniti nelle precedenti annualità, dal punto di vista politico, economico, sociale e culturale. La seconda parte, invece - Idées et événements - suddivisa in sezioni tematiche, fa il punto della situazione delle attività più importanti svoltesi nell'anno passato riguardanti la francofonia. Vengono innanzitutto messe in rilievo la diffusione e l'evoluzione degli studi francofoni condotti nei paesi non francofoni grazie ad un état des lieux delle diverse attività e ricerche frutto della collaborazione con numerosi gruppi di ricerca internazionali che, fotografando la situazione del proprio paese, mettono in luce diversi orientamenti e nello stesso tempo interessi comuni. Il grande convegno internazionale sulla francofonia americana che ha avuto luogo il 26-29 maggio 2003 riveste un ruolo centrale in questo numero: tenutosi in occasione del $400^{\mathrm{mo}}$ anniversario dell'arrivo di Champlain in America del Nord, il convegno ha infatti rappresentato un momento di riflessione sui rapporti tra America, Africa ed Europa attraverso la lente d'ingrandimento della francofonia, ed è stato l'occasione per un avvicinamento con le comunità amerindiane. L'anno di cui la rivista rende conto, inoltre, dimostra un crescente interesse verso progetti che, nell'ottica della francofonia, coinvolgono i giovani nelle differenti discipline, dall'arte allo sport, e che creano legami e comunicazione tra un'area e l'altra. Articoli che approfondiscono temi 
letterario-linguistici affrontano le problematiche delle lingue nate dalla fusione di francese e lingue autoctone in quanto lingue letterarie, come nel caso del Bénin o quello della letteratura kanak francofona. Sempre nell'ottica dei legami con le comunità amerindiane, viene presentata l'opera di Michel Noël, scrittore quebecchese che ha vissuto i primi anni della vita a stretto contatto con queste realtà sociali, e che esprime nei propri testi una visione del mondo métisse. La sezione letteraria presenta l'attività delle scrittrici emergenti senegalesi (Fama Diagne Sène) e di alcuni scrittori dell'est europeo che si esprimono in francese - la giovane Anca Visdei (Sylviane Roche) e Matei Viflniec (Laurent Lorrion), entrambi di origine rumena, e la poetessa Blaga Dimitrova (Tzvetan Todorov) - di Henry Bauchau (Sylviane Roche) e un saggio sulla trattazione del tema dell'amore in epoca contemporanea (Marc Quaghebeur). Tra i prodotti cinematografici domina il successo internazionale de Les invasions barbares di Denys Arcand. Con uno sguardo trasversale viene messo in rilievo il carattere di sovversione che, in modalità differenti, accomuna la ricerca drammaturgica francofona (Dany Toubiana). Tre articoli sono rispettivamente dedicati a una pièce algerina, a una della zona dell'Oceano Pacifico e a una senegalese. La prima, di Slimane Bénaïssa $\mathrm{Au}$ delà du voile si ambienta in Algeria e si interroga sulla condizione della donna in ambito familiare (Dany Toubiana); la seconda, scritta a quattro mani da Nicolas Kurtovitch e Pierre Gope mette in scena temi attuali per la zona francofona del Pacifico, primo tra $\mathrm{i}$ quali quello dell'assenza di un valido leader politico e della presenza del denaro europeo, che determinano un problema identitario per la popolazione (Dominique Jouve). La terza è Papa doit manger della giovane Marie Ndiaye.

2 Le ultime sezioni della rivista si pongono come obiettivo quello di considerare la francofonia in relazione alla globalizzazione, come fenomeno attuale non privo di contraddizioni e di problemi da affrontare. La francofonia come istituzione, dunque, come viene messo in rilievo nella sezione dedicata all'Organizzazione Internazionale della Francofonia. 